\title{
Emotional Themes within International Adoption Children's Books
}

\author{
Jacki Fitzpatrick \\ Erin Kostina-Ritchey \\ Texas Tech University
}

*Please address correspondence to Dr. Jacki Fitzpatrick, Department of Human Development and Family Studies, Texas Tech University, 507 College of Human Sciences, Mail Stop 1230, Lubbock, Texas 79409-1230. Email:

Jacki.Fitzpatrick@ttu.edu.

Authors Note: ${ }^{1}$ Throughout the manuscript, the term "parent" refers to adoptive parents only. Although birth parents play a significant role in adoptees' lives, none of the birth parents were represented in the quotes listed in the Results section. ${ }^{2}$ Some derogatory terms have been listed in children's books and professional publications about adoption. In some journal articles (e.g., Rathbun \& Kolodny, 1967), the authors might have simply been reporting the terms that were used by adoptive parents and/or the general community. In children's books, it is possible that the terms were more acceptable in prior decades. Similar to other forms of adoptive/racial representation (e.g., games, masks), individuals might have become more sensitive to the derogatory meanings over time (Song, 2004). Thus, the authors might not have had negative intentions (e.g., derision) in their use of such terms during that particular timeframe. Regardless of authors' intentions, adoptive parents might be less inclined to share such storybooks with adoptees.

\begin{abstract}
In the context of Greenspan's (1988) Emotional Milestones Model for child development, this qualitative study explored the emotional themes displayed in children's picture books about transracial international adoption. The books $(n=24)$ were coded independently by two researchers. Two primary themes from the transition literature (trepidation, wonder) were evident in the content analysis. The results are consistent with the adoption literature, which suggests that an emphasis on transparency is most beneficial to adoptive family adjustment. Implications for practitioners and researchers are noted.
\end{abstract}

Keywords: Greenspan's Emotional Milestones Model, Trepidation and wonder, Transracial international adoption, Picture books, Qualitative content analysis. 
International adoption is a significant process for parents ${ }^{1}$ and children (Suter, 2008). In addition to the obvious change (one or more children are added to a family), adjustments might be made in physical and psychological space (Janning, Collins \& Kamm, 2011) as parents adapt to the roles of motherhood or fatherhood (Curtis, Blume \& Blume, 1997-1998) and children adapt to multiple changes in most aspects of their lives (e.g., Pinderhughes, 1996). Children might be too young (e.g., infant, toddler) at the time of adoption to fully comprehend the event, yet they are likely to have some awareness. Adoptees can recognize a change in caregivers or environments, even if they do not understand the reason for the change (e.g., Murphy, 2009). Changes can be more dramatic in international adoptions. For example, Chinese adoptees and U.S. parents might face linguistic barriers to their communications. In addition, it should be noted that racial/ethnic/cultural differences (in Chinese-US transnational adoptions) might add to a sense of unfamiliarity among children and adults (e.g., Royle, 2004).

Under these circumstances, it can be helpful to consider the emotional reactions of children and parents to the adoption process. Information about these processes can be provided in a variety of venues, including children's books. The purpose of this study is to examine emotional themes in children's picture books about international adoption. Song (2004) noted that books are the resource most commonly used by adoptive parents. These books can describe the logistics of the process, so that children receive an explanation of how adoptions occurred. Perhaps more importantly, the books identify the common changes in family relationships and interactions (e.g., Grice, 2005). As adoption is an elongated process with many unknown elements (e.g., how long it will take, who the adopted child will be), this process can evoke many emotional reactions (e.g., Leon, 2002; Suter, 2008). Parents might also not know or be able to gather information about the child's birth family (Ponte, Wang \& Fan, 2010). Thus, the families might face doubts, questions or moments of trepidation that do not occur commonly in other family formation patterns (Miall, 1987; Raible, 2008). In addition, children's questions and identity issues can occur years after the adoption has been completed (Ponte, et al., 2010). Thus, the books can serve a retrospective function in helping children understand the ways adoptees and parents respond to various aspects of the adoption process.

In addition, the books are consistent with narrative psychology principles, in which individuals and families create meaning through the stories that they share (in oral or written form). Books for very young children can address serious themes and provide models for psychological growth in response to new information (e.g., Dyer, Shatz, \& Wellman, 2000). Narratives about family formation are particularly important to adoptees (e.g., Kranstuber \& Kellas, 2011), and some remember the adoption books that were read to them in early childhood. Indeed, some adoptees have described the ways in which the books continue to influence (in adulthood) their images of themselves and their families (Jue-Steuck, 2011). 
If the books address a range of emotions, then books might be a valuable resource to validate the children's and parents' experiences. Indeed, such books have been recommended by adoption agencies (e.g., Families with Children from China, 2011; Little Miracles Adoption Services, 2012), public periodicals (e.g., Parents Magazine, 2012) and clinicians/service providers (e.g., Kavanaugh \& Fiorini, 2009). Based on the premise that children's self-concept is affected by the words/images that they see in fictional texts, researchers have conducted content analysis on issues such as racial and gender representation within the books (e.g., Roethler, 1998; Taylor, 2003). However, there has been less attention given to an examination of transracial international adoption children's books. One conceptual framework that can be used to guide this examination is Greenspan's (1988) model for emotional milestones.

According to Greenspan (1988), there are specific stages of emotional development that occur during childhood. Emotional development occurs simultaneously or in concert with other forms of growth (e.g., intellectual, sensory-motor, physical). Thus, emotional growth is simply part of the whole child perspective. Greenspan and Porges (1984) noted that emotional development and relational processes are strongly linked. Children's emotional adaptation is directly affected by the degree and quality of responsiveness that they receive from caregivers/parents. Adults who can read and respond effectively to children's needs create an environment that facilitates children's healthy emotional development.

During the late infancy/toddler periods, emotional development is focused on integration and innovation of emotional patterns (Greenspan, 1988).

According to DeGangi, DiPietro, Greenspan and Porges (1991), children are exposed to many phenomena which they interpret and respond emotionally (e.g., fear, pleasure). They have an emerging self-awareness and attempt to make sense of the ways in which they exist in relationships with others (Greenspan, 1988). Children recognize that not all adults are the same and they can have preferences for specific individuals. Young children might not be able to articulate all of their experiences, but their awareness can be quite acute (Greenspan \& Porges, 1984).

During these same periods, adult caregivers (including parents) foster infants/toddlers' emotional development via their responsiveness (Greenspan, 1988). Caring adults attempt to read accurately and react to emotional cues, but it is acknowledged that their efforts are not always successful. As one element of development is a growing autonomy, children have emotional states that are separate from adults (Greenspan, 1988). This autonomy is also reflected in children's developing sense of identity. Thus, adults accept that children might not share their emotional states or respond in ways that adults desire. Adults who are sensitive and open to understanding the range of children's experiences promote healthy emotional development. This sensitivity might be particularly helpful during significant transitions, such as adoption.

Transitional states occur when individuals, families or groups have changed to some extent, but have not completed the change (e.g. White, 2005). Sample transitions include college adjustment (Winkle-Wagner, 2009), 
serious/chronic illness (e.g., Bournes \& Ferguson-Paré, 2005), and incarceration of parents (Baumann, 2000). The resolution of the transition might be out of their control, and no one might actually know how the situation will end. Thus, individuals can be in a state of flux for months or years at a time. Under these conditions, it can be difficult for individuals or families to have a single response to the experience. Rather, the meaning of the event/process can change repeatedly as the context and meaning changes (Janning, et al., 2011).

The Greenspan (1988) model highlights common emotional elements across phases of child development. This model can be useful, but it lacks details about the (a) valence of emotional states or (b) specific contexts. For example, the model does not delineate the types of emotions that would be common to young children during the adoption process (e.g., leaving caregivers, meeting new parents). Yet, it seems reasonable that negatively-valenced emotions (e.g., anxiety, fear) would be appropriate for children during the adoption transition. In order to explore emotional states (within the books), the Greenspan (1988) model was supplemented with concepts drawn from prior research on personal and relational transitions.

The transition literature has identified that negatively and positively valenced emotional reactions can occur. The negatively valenced reactions have been labeled as dispirited trepidation (Bournes \& Ferguson-Paré, 2005). Dispirited trepidation is evident when individuals experience emotions such as doubt, fear, worry and insecurity. In addition, they can experience a lack of connectedness, such that people who do not share their condition do not understand their experience (Winkler-Wagner, 2009). This lack of connectedness can also occur when individuals cannot fully articulate their needs or have their desires met. Given the high hopes that parents might have for unions with adoptees, it is possible that parents feel trepidation if the experiences are different than what they expected. Similarly, it might be possible for adoptees to be portrayed in books as experiencing trepidation when they encounter new parents who are initially strangers to them.

The positively valenced emotions are reflected in the concept of wonder (Rumford, 2008). Wonder is not simply an intellectual curiosity that is devoid of emotion. Rather, wonder is evident in anticipation, excitement and delight. If they are open to experiences, individuals might find pleasures or moments of connection that did not necessarily occur as they expected (Baumann, 2000). Even if family members make sacrifices or have to endure challenges, then they might decide that the sacrifices are worth the relationship gains (Bischof, Warnaar, Barajas, \& Dhaliwal, 2011). Thus, some books might portray parents as delighted during various phases of the adoption process (e.g., application approval, meeting the child). Similarly, it is possible that some children might be portrayed as having a warm response to adoptive parents.

In sum, this study focused on the ways in which adoptees and adoptive parents' emotional responses were portrayed in children's books about transracial international adoption. Emotional responses can vary across the lifespan, so Greenspan's (1988) model of emotional milestones as used as a guide to identify 
the elements of children's emotional representation. In addition, this model was used to identify the elements of responsiveness by adults toward the adoptees portrayed in the books. Given that adoption is a transitional experience for families (Miall, 1987; Ponte, et al., 2010), the transition literature was used to identify the negatively (trepidation) and positively (wonder) valenced emotional states. Thus, the current study addressed the following research question: Are the emotional themes of trepidation and wonder evident in preschool children's books about international adoption?

\section{Method}

\section{Sample of Children's Books}

The data for this study were children's picture books that focused on adoption of Chinese daughters by U.S. families. As there are significant cultural variations across Asian countries (e.g., Pang, Han \& Pang, 2011), it was important to limit the books to a single country. This limitation assured that any variations in books were not due to differences in birth countries/cultures (e.g., South Korea, Cambodia, Singapore). Additional criteria for inclusion in this study were that each book must be (a) written at a preschool-kindergarten level, (b) publicly accessible [via bookstores, libraries], and (c) published after 1996. Books were limited to the preschool-kindergarten level because these books might serve as children's first stories about adoption. Similar to other dimensions of identity (e.g., gender), children's books can have a significant impact on their sense of self and others (Diekman \& Murnen, 2004).

The books were limited to recent publication for three reasons. First, the number of adoption of Chinese children by US families increased dramatically during the late 1990s-2000s. Two hundred and six children were adopted in 1992, 3,333 children were adopted in 1996, and 6,062 children were adopted in 2002 (Holt International, 2011). This represents a nearly a 3000\% increase in adoptions during this ten-year period. The children's literature was somewhat consistent with this trend, as more books about adoption were published during this time frame. Second, recently published books appeared to be more easily accessible via public sources. Although it was not inherently difficult to find information about older books, it was more difficult to gain access to the actual books [e.g., libraries, bookstores]. If adoptive parents found the same challenges in gaining access to older books, then they might be more likely to use books that are more recently published and easily available. Third, older books contained some terms (in reference to Asian ethnic identity/culture) that might have been considered socially acceptable at the time, but are currently considered derogatory. ${ }^{2}$ If children are exposed to derogatory terms about their racial/ethnic heritage, then it is possible that such exposure might affect Chinese adoptees' identity development by early adolescence (Tessler, Han \& Hong, 2005). Similar to other adoptive families that face challenges in racial/ethnic identity for their children (Song, 2004), it is possible that US adoptive parents seek to protect their 
Chinese daughters from exposure to such terms. Thus, parents might be more likely to use more recent (and less derogatory) books.

A variety of resources (e.g., adoption websites, parenting magazines, library lists) were used to locate potential books. A total of 24 books were identified that met the inclusion criteria. Two books included dual perspectives (e.g., parent and sibling views of the same adoption process), so a total of 26 stories were coded. The majority of books represented an adoption which took place while the adoptees were infants $(n=24)$. If Chinese daughters were similarly adopted during infancy/toddlerhood, then it is possible that they do not have clear memories of their own adoption experiences. This possibility is consistent with the general literature on child development (McDevitt \& Ormrod, 2007), and specific research on (a) infant/toddler memory (Lindholm et al., 2009), (b) domestic adoption (von Korff, Grotevant, Koh \& Samek, 2010) and (c) ChineseUS adoptive families (Ponte, et al., 2010). Indeed, parents are encouraged to read stories early and repeatedly to help children make sense of the adoption process (e.g., Kennedy, 2006).

The stories were typically presented from one of four perspectives: (a) adoptive mother or father; (b) sibling [who was part of the family prior to the current adoption]; (c) adoptee; or (d) third person viewer/narrator [e.g., 'Martha and Jose adopted a baby'.]. Thus, multiple voices or viewpoints were represented. Temporally, the books were written in current [what is happening today] or retrospective [how the adoption occurred] formats.

\section{Coding Procedure}

Two researchers engaged in conventional content analysis (Hsieh \& Shannon, 2005). Independently, each researcher read each book. Initial codes were identified for the books' texts. Text was coded for both manifest and latent content (Graneheim \& Lundman, 2004), with the major themes (Braun \& Clarke, 2006) of trepidation and wonder being identified. Initial interrater reliability for the themes was .89. A constant comparative method (Bogdan \& Knopp Biklen, 1982) was used when the researchers had a discrepancy in coding a specific portion of text. More specifically, the researchers perused the book portions again and engaged in a series of analytic discussions until clarity was achieved. Across the layers of the coding process, each book was read twelve times (six times by each researcher).

\section{Results}

\section{Negatively Valenced Emotions (Trepidation)}

Consistent with the literature on actual adoptions (Docan-Morgan, 2011; Miall, 1987), negatively valenced emotional moments were evident in the books. These moments were described for both adoptive parents and children. Trepidation was seen across various points in the adoption process (e.g., preadoption preparations, family and adopted child together in China, post-adoption life in the US). 
Consistent with the literature on young children's awareness (e.g., Bergen, 2008), one reason that children experience negatively valenced emotions is they do not have an accurate understanding of the adoption process. Accuracy might be beyond the range of infants and toddlers, but they might still attach emotional meanings to the words they hear in reference to adoption. In one story, a caretaker has been repeatedly telling an adoptee $(\mathrm{Li} \mathrm{Li})$ that she will have a 'family'. However, the child does not know the meaning of the word: "A mommy with golden hair, a daddy with hair that looked like salt and pepper, and a big sister who said, 'My dream has come true'!... 'So this is a family,' thought Li Li. 'But I hoped that it could bounce on it, or that it would make pretty music, or that it would taste yummy. I thought maybe it would be soft, and I could cuddle it'," (The Long Ride a Child's Search). This child's reaction is congruent with Greenspan's (1988) argument that young children form imagery of objects/other people. When there is discordance between imagery and reality, then children can be disappointed.

A more overt emotional expression was evident in the portrayal of another child. Although the nanny has been telling the child repeatedly that she will be adopted, the child is still distressed when leaving the orphanage: "Shaking, I leaned against my nanny, worrying about leaving the babies' room...I felt afraid and didn't want to leave... 'Say good-bye,' my nanny whispered. I turned in her lap and looked at the building that was my home get smaller as we drove away. I cried and snuggled in closer to my nanny." (My New Mommy, How I Got Adopted). This description reflects the complex behavioral and emotional patterns that young children can experience (e.g., Greenspan \& Porges, 1984). Children can recognize that changes are occurring and have some distress, even if they do not understand the exact nature of the changes (e.g., McDevitt \& Ormrod, 2007). Under such circumstances, infants/toddlers can initiate contact with caregivers (e.g., Greenspan, 1988).

As adoptees move from infancy to childhood, their sense of identity emerges. Thus, awareness of the adoption and familial process might only be concerning as they gain new knowledge (e.g., Ponte, et al., 2010). One book described an adoptee's fear as she tried to comprehend the differences between her and her mother's familial lineage: "'When did your mommy get you from China?' I asked my mother one day. Mommy said that she did not come from China. She was born in America. 'I thought all babies come from my China.' 'No, honey.' My mommy's voice was soft. 'Babies come from inside their mommy, Elizabeth.' 'But mommy,' I said, 'I always thought I came from my China.' I felt afraid." (Mommy Far, Mommy Near). This fits with the proposition that toddlers' emotions are tied to their mental representations of themselves and their relationships (Greenspan, 1988). As adoptees learn the distinction between their birth parents and adoptive family lineage, this knowledge can create changes in their view of family. A sense of dual family heritage can be a more complex concept and define personal histories that existed separately for parents and children prior to the adoption (e.g., Pinderhughes, 
1996; Ponte, et al., 2010). It is not surprising that recognition of such differences might be frightening for a young child.

The books indicated that adults also experienced some negatively valenced emotions when they recognized some issues. For example, some books revealed parental insecurities or worries about building bonds with adoptees: "Andrea Lee wrote in her journal, 'I wonder if Li Shen will cry when I hold her. Will I be able to comfort her?'... Howard Suzuki looked at the photo of Chun Mei Ni and wondered if she would love him." (The White Swan Express). It might be argued that such questions might not reflect worry, but rather reflect a neutral curiosity. However, the importance of the response to such questions (e.g., Will an adoptee love a parent?) does not suggest neutrality. According to Greenspan and Porges (1984), well-adapted children have caregivers who are emotionally available to help children understand their experiences. The books portrayed both parents as being open (rather than emotionally unavailable). However, the openness did not assure that (a) parents would be successful in meeting the children's needs and/or (b) children would like/love the parents in return.

Indeed, several books portrayed that there were often struggles, in which parents and/or children did not demonstrate instant bonds. Although one or more individuals might attempt to communicate, the attempts were not always successful. For example, one mother describes her first day with her new daughter in the following way: "When we reached our hotel room, I showed you the view of the city. You wriggled in my arms again, and I pulled you closer. 'This is new for me, too,' I said. 'I've never been here before either.'...But you weren't listening...You looked everywhere but at me." (The Red Blanket). This portrayal is consistent with research/clinical practice with actual adoptive families (e.g., Pinderhughes, 1996), in which parents were not able to read and/or respond to children's emotional cues. This description might also be consistent with the actual transitions literature (Winkle-Wagner, 2009), in that individuals can experience disappointment when others fail to understand the nature or importance of an event. Although parents might see the first day together (with children) as a momentous occasion, children might simply experience the day as a series of unfamiliar or distressing events. Thus, adults and children can be physically close, but in emotionally disparate places.

\section{Positively Valenced Emotions (Wonder)}

Similar to negatively valenced emotions, positively valenced emotions (wonder) were evident in the children's books. Some emotional expressions occurred early in the adoption process, whereas other expressions occurred months after the family had settled in the U.S. For example, one described a child's dreams after the first day with her adoptive mother: "I dreamed happy dreams. I dreamed about my forever Mom, Bo and our new family. I dreamed about China. And whatever or wherever I dreamed, Bo was right along with me, holding my hand. 'I will always be with you,' he said to me. 'I was always with your Mom and now we're both with you." (Families are Forever; [Note: Bo is a toy hippo.]). Although the emotional expression occurs in the context of dreams, 
dreaming is not the primary element. Rather, dreams simply serve as a narrative vehicle to delineate imagery of newly forming family relationships. This formation process is consistent with Greenspan's (1988) description of adaptive emotional capacities for young children.

In contrast, some books did not portray an instant sense of connectedness to new parents. One story presented that an adoptee was closer to the father than the mother. The child does not refer to her as 'mother' until an event that occurred some months after the initial adoption: "Then one summer day the woman took me to the park. She lifted me high and placed me on a swing. She smiled, but I turned away. The swing began to sway. I could see the sky slip and the ground rise. The wind rushed over me. I was falling! But before I fell all the way, the woman reached out and caught me. I looked up into her round gray eyes and called her Mommy. Her eyes sparkled brighter than the sun."(An Mei's Strange and Wondrous Journey). Although the child might have been frightened by the falling sensation, she recognizes that the 'woman' is responsive to her needs. This recognition might have facilitated the child's transformative identification of her (from 'woman' to 'Mommy'). This transformation fits with Greenspan and Porges' (1984) notation that toddlers can experience an emergence of insight and make differentiations in their identifications with significant others.

An elongated process was also portrayed in a child's reaction after she understood her adoption history. After the mother explained the entire adoption process, the child identified a sense of belongingness in their relationship: “"...we love each other, just as we are. And I love you-just as you are,' her mom said. Then she gave Laura a big hug. Her mom's hug made Laura feel happy and secure. 'Mommy, 'Laura said, 'I love you- just as you are.'"(A China Adoption Story). This description parallels Greenspan's (1988) notation about stabilization. If responsive caregivers guide children gradually to understand reality, then children can feel safe and secure in the context of new information.

Stabilization was similarly evident in portrayal of a father's comfort after a child has become frightened of a nighttime noise: "Daddy came in, listened, and pointed. It was only the leaves of the bamboo tree brushing against my windowpane. I climbed into my bed... When he thought I was asleep, he kissed my forehead, tucked my blanket around me, and turned off the light. Then he tiptoed out. I knew I was safe. "(An Mei's Strange and Wondrous Journey). It is true that parents (in all family forms) can address nighttime fears, but comfort might be particularly salient to international adoptees as they adjust to a new house in a new land. The father's comforting actions is consistent with Greenspan and Porges' (1984) argument that children benefit from parents who are sensitive to their dependency needs.

It should be noted that positively valenced emotional expressions were not limited to children. Parents were also portrayed as experiencing dimensions of wonder or delight. These expressions often occurred prior to meeting their adopted children. For example, one mother shared her excitement with her son when they received letter notification that an adoption had been approved: "'Oh, that's the letter I've been waiting for!' She grabbed the letter, tore it open, and 
read it...Matthew, this is your new baby sister!' Mom said. 'Really?' Matthew picked up the photo. He looked at Mom. Mom laughed, put her arm around Matthew, and squeezed him tight. 'This little girl lives in an orphanage in China. We are going to adopt her and make her a part of our family. Isn't that wonderful?"'(A Story about Adoption).

Given that the books were written at a preschool-kindergarten level, there were elements of anthropomorphism (giving human qualities to inanimate objects). Thus, toys were treated as members of the family who also shared in the anticipation. Bo, a stuffed blue hippo, was a lonely toy who wanted a child of his own with whom to play. So, both Bo and the human mother were thrilled when the Bo overheard her say on the phone: "'It's a little girl! Isn't that wonderful? I'm going to China to bring her home.' When Bo heard her say that, he got excited, too." (Families are Forever). Anticipation was also evident in restlessness on the day of travel to China: "Lewis Maynard was awake. He sat by the window waiting for dawn. When the sun came up, he looked at his watch, then looked at his wife and burst into song. 'It's a beautiful day-hey! Hey! Hey! To be on our way" (The White Swan Express). In all three of these books, the emotional expression was not portrayed as directly shared with the adopted child. Rather, the expressions were in reference to the adopted child. This enthusiasm for collectiveness (the child will be part of the family) is congruent with the premise that effective parents make themselves emotionally available to their children (e.g., Greenspan, 1988).

Other books also described wonder or delight after the union between parents and children. Consistent with literature on openness to new possibilities during actual transitions (Rumford, 2008), delight was often described in the context of spontaneous events. The delight reflected happiness for the particular moment, event, or person. For example, a mother described the family's reaction after a daughter ate ice cream: "Once you started laughing, you kept going. Laughing and laughing. Loudly. We thought it was wonderful. Except for the time we gave you ice cream. I know you like ice cream. But this ice cream made you so silly. You were running, shouting, bouncing off the walls. Daddy and Conor tried to catch you. We looked like we were making a funny movie. "(Just Add One Chinese Sister). This description is consistent with Greenspan and Porges' (1984) notation that responsive parents set limits for their children, but also allow for some autonomy. Thus, parents balance the needs for guidance and freedom in children's emerging range of emotional expression.

\section{Discussion}

The purpose of this study was to identify whether emotional themes of trepidation and wonder were evident in preschool children's books about international adoption. Both themes were evident in the books. These themes were examined in the context of Greenspan's (1988) description of adaptive emotional processes for young children (e.g., late infancy-toddlerhood). The books' portrayal of adoptive families fit with Greenspan's (1988) developmental model as well as the literature on life transitions. 
As noted previously, Greenspan and his colleagues (Greenspan, 1988; Greenspan \& Porges, 1984) identified elements of emotional expression that they argue represent adaptive development among children. These elements include the cognitive/emotional skills of children (e.g., insight, imagery, expressiveness) and responsiveness of adult caregivers (e.g., openness, sensitivity, willingness to set limits). Responsive adults provide a safe environment in which children can explore their environments and relational processes (Greenspan, 1988). The majority of books utilized in this study focused on relatively brief periods of time in the adoption process. Nevertheless, the books portrayed powerful and specific emotional expressions. These portrayals appeared to be highly consistent with Greenspan's (1988) description of discrete elements, such as creating imagery, making meaning, reading and responding to cues. The books also identified expressions by both children and adults. Consistent with Greenspan and Porges (1984), the books suggested that children have a rich emotional world, even if children's comprehension of significant changes (such as adoption) is limited.

More globally, the books were also consistent with the literature on actual transitions. Similar to prior studies on life transitions (e.g., Baumann, 2000; Bischof, et al., 2011), the books portrayed adoption as an elongated and ambiguous process. Even books that told the stories in retrospective form (how the adoption occurred in prior years) often revealed that there were moments of fear, worry, excitement, joy or surprise through the adoption process. Thus, books did not typically present adoption as a simple or direct process. Consistent with prior studies on the transition to biological parenthood (e.g., Curtis, et al., 1997-1998), adoptive parents were portrayed as having concerns about their connectedness with children and/or their abilities to meet children's needs. Such portrayals might not reflect negatively upon adoptive parents. Rather, these portrayals might reflect the parental efforts to be sensitive to adoptees.

It should also be noted that the books portrayed a range of emotional responses by children. Similar to the literature on actual adoptions (e.g., Pinderhughes, 1996; Suter, 2008), the books did not uniformly describe instant bonds between parents and children. Some children were portrayed as developing a quick sense of emotional security, whereas others developed connections to parents only after an extended period of time. Consistent with the acknowledgement of loss (e.g., Jue-Steuck, 2011; Leon, 2002; Murphy, 2009), some stories described children's distress at leaving their locations (orphanages) or caregivers (e.g., nannies). Thus, the books were quite transparent about the emotional range that can be experienced during the adoption process.

\section{Implications for Practitioners}

Given that the books are publicly accessible and easily attainable by adoptive families, it seems worthwhile for family service providers/practitioners to familiarize themselves with these books. Similar to other forms of bibliotherapy (Goddard, 2011), practitioners might find that the books facilitate families' adjustment processes. However, practitioners will also find it helpful to

critically analyze the books. Prior critical analyses have indicated that, regardless 
of good intentions, media and adoption activities can convey messages of otherness or inferiority (Kelly, 2002). For example, Song (2004) described the ways in which events (such as summer camp games) and items (such as Halloween masks) reinforced negative stereotypes about Asian identity, ignored the financial realities that low-income Asian families face, and minimized social accountability about discriminatory practices. Given the counterargument that children are too young to (a) recognize these messages and/or (b) integrate into their self-image, it can be challenging to alter such activities. Yet, adoptive identity can begin in early childhood and last a lifetime (e.g., Docan-Morgan, 2011; Grotevant, Dunbar, Kohler, \& Esau, 2000). Some adult adoptees have reported that they still remember books that were read to them in childhood and these books remain part of their adoption identity (Jue-Steuck, 2011). Given this potential influence on young children, it would be worthwhile for practitioners to (a) familiarize themselves with these fictional books and (b) utilize their knowledge to supplement and/or ameliorate some of the messages within the books.

Practitioners might also need to consider long-term identity issues for transracial international adoptive families. These identity issues were beyond the purview of the present study, but of some prominence in the literature on actual adoptions. Consistent with adoption trends (e.g., Holt International, 2011), the books focused on adoption of Chinese daughters by US families. When parents' ethnicity was portrayed in the books (e.g., via illustration), $90 \%$ of parents were portrayed as White/Caucasian. Thus, the racial/ethnic differences between adoptees and adoptive families (e.g., grandparents, parents, siblings) would be apparent to everyone inside and outside the family Although some countries tend to focus on de-emphasizing differences in transracial adoptive families (San Román, 2011), this has not been the trend within the US. Rather, there has been an emphasis that parents should be mindful of these issues and facilitate discussions/opportunities for their children to make sense of their biological and cultural history (e.g., Lebner, 2000; Suter, 2008). For example, some families travel to China in an effort to expose their older children to their country of origin and cultural heritage (Ponte, et al., 2010). In addition, parents focus on strategies to address public reactions (e.g., from neighbors, strangers) to their adoptive families (Miall, 1987; Suter, 2008; Wegar, 2000).

Although some parents are proactive and successful in fostering identity development for their adopted children, other parents might struggle. These parents might want to provide support for their children, but lack sufficient resources (e.g., conversational skills, knowledge about racial/ethnic identity). It is also possible that these parents are so concerned with other elements of the child's adjustment (e.g., education, bond with siblings) that they treat race/ethnicity as a lower priority issue. It should also be noted that some might actively avoid the issue because they abide by a 'love is blind' view of adoption. In this case, parents might presume that racial/ethnic differences are irrelevant if a child feels truly loved. 
However, adoptees might not share their parents' view or experiences with race/ethnicity. As adoptees grow past the infancy/toddler stages, they have an emerging sense of self (Bergen, 2008). Race/ethnicity is part of their identity throughout their lifetimes. If adoptive parents are uncomfortable or ill-equipped to address identity issues, then adoptees are left to their own developmental resources. Indeed, parents' unwillingness to address issues can be seen as a form of criticism or rejection (e.g., Docan-Morgan, 2011). Under such circumstances, all family members might benefit from the leadership of adoption practitioners. Practitioners can guide open dialogues about relevant issues and even conduct group sessions in which parents practice discussions about identity issues (e.g., San Román, 2011). In addition, practitioners can help parents to recognize racially appropriate (and inappropriate) resources (e.g., toys, games, imagery) for their children (Song, 2004). If parents become comfortable with identity issues, then they can guide their children's emotional development and model healthy communication strategies for their children.

\section{Strengths, Weaknesses and Recommendations for Future Research}

The results should be considered in the context of the study's strengths and weaknesses. Compared to prior analyses of adoptive literature (e.g., Ayres, 2004), this study utilized a larger sample of books. The larger sample increased the likelihood of identifying elements of emotional expression within children's books about adoption. In addition, selection criteria were utilized to enhance the uniformity of book characteristics. This utilization decreased the likelihood that any relational variations were due to demographic factors (e.g., age, gender, birth country of adoptees). More generally, the researchers followed qualitative research guidelines (e.g., Bogdan \& Knopp Biklan, 1982; Patton, 2002) to enhance the likelihood of an accurate analysis of the book themes. For example, the books were initially read and coded independently by each researcher and then researchers engaged in discussions to attain consensus. Another strength is that the researchers utilized a conceptual framework (e.g., Greenspan, 1988) to guide the analysis of emotional themes. In addition, the study identified linkages between (a) fictional stories and (b) emotional themes evident in scientific literature on actual transitions (e.g., Bournes, \& Ferguson-Paré, 2005; WinkleWagner, 2009).

In contrast to the strengths, there were some weaknesses. The study was limited to a nonrandom sample of books and focused on adoption of Chinese daughters. Thus, the results might not be generalizable to more diverse books or adoption populations. As this study focused on fictional books, it is not known how accurately the books portrayed families' adoption experiences. It also is possible that the books accurately reflect adoption dynamics at a particular point in time, but dynamics are not static. Rather, the emotional processes and meaning attached to them can change as adoptees grow into middle childhood (e.g., Royle, 2004) or adulthood (e.g., Docan-Morgan, 2011). Thus, the books might represent only part of the adoption experience. In addition, it is not known how frequently the books are used by adoptive families. The researchers attempted to identify 
books that were commonly identified and/or recommended by adoption and parenting sources. However, no national data source on actual book usage (e.g.., number of times read) could be identified. This limitation is not limited to adoption books, but rather applies to many aspects of content analysis research. In light of these weaknesses, recommendations for future research are offered. Researchers should conduct analyses of adoption fiction that represents greater diversity (e.g., older children, males, children from other countries). It might also be possible to inquire about adoptive families' actual use of the storybooks. Quantitatively, researchers can access factors such as (a) number of books read by families, (b) frequency with which books are read, and (c) rank order [best-worst] of families' preferences. Qualitatively, researchers should conduct focus group interviews with adoption professionals and adoptive parents to assess the meaning which they assign to the books, or recommendations that they would offer for book authors. In addition, it might be possible to use the books as a resource in prospective or retrospective studies. Prospectively, the books can be utilized to assess relevance to familial emotional processes as adoptees move from early childhood to middle childhood. Retrospectively, the books could be used as a resource to facilitate memory recall for adults who were raised in adoptive families. This retrospective approach would be consistent with prior studies on adoptees (e.g., Docan-Morgan, 2011) and siblings (e.g., Raible, 2008).

\section{Conclusion}

This study examined the ways in which the emotional processes of trepidation and wonder were evident in children's books about adoption. The specific elements of the processes were examined in the context of Greenspan's (1988) model of emotional (developmental) milestones. In comparison to actual adoption experiences, children's books might seem to be rather trivial. However, the books portrayed the complexity of both positively and negatively valenced interactions in newly formed adoptive families. Thus, the books appeared to treat these issues with respect and transparency.

\section{References}

Ayres, S. (2004). The hand that rocks the cradle: How children's literature reflects motherhood, identity and international adoption. Texas Wesleyan Law Review, 10, 315-342.

Baumann, S. L. (2000). The lived experience of feeling loved: A study of mothers in a parolee program. Nursing Science Quarterly, 13, 332-338.

Bergen, D. (2008). Human development: Traditional and contemporary theories. Upper Saddle River, NJ: Pearson.

Bischof, G. H., Warnaar, B.L., Barajas, M.S., \& Dhaliwal, H.K. (2011). 
Thematic analysis of the experiences of wives who stay with husbands who transition male-to-female, Michigan Family Review, 15, 16-34.

Bogdan, R.C., \& Knopp Biklen, S. (1982). Qualitative research for education: An introduction to theory and methods. Boston, MA: Allyn and Bacon.

Bournes, D. A., \& Ferguson-Paré, M. (2005). Persevering through a difficult time during the SARS outbreak in Toronto. Nursing Science Quarterly, 18, 324-333.

Braun, V. \& Clarke, V. (2006). Using thematic analysis in psychology. Qualitative Research in Psychology, 3, 77-101.

Curtis, J.A., Blume, L. B., \& Blume T.W. (1997-1998). Becoming a father: Marital perceptions and behaviors of fathers during pregnancy. Michigan Family Review, 3, Retrieved June 4, 2011 from http://quod.lib.umich.edu/m/mfr/4919087.0003.104?rgn=main;view=fullte $\mathrm{xt}$.

DeGangi, G.A., DiPietro J.A., Greenspan, S.I., \& Porges, S.W. (1991). Psychophysiological characteristics of the regulatory disordered infant. Infant Behavior and Development, 14, 37-50.

Diekman, A., \& Murnen, S. (2004). Learning to be little women and little men: The inequitable gender equality of nonsexist children's literature. Sex Roles, 50, 373-385.

Docan-Morgan, S. (2011). "They don't know what it's like to be in my shoes": Topic avoidance about race in transracially adoptive families. Journal of Social and Personal Relationships, 28, 336-355.

Dyer, J., Shatz, M., \& Wellman, H. (2000). Young children's storybooks as a source of mental state information. Cognitive Development, 15, 17-37. Families with Children from China. (2011). Books. Retrieved January 30, 2012 from http://fwcc.org/index.php?option=com_content\&view=category\&id=22:b ooks\&Itemid=11\&layout=default.

Goddard, A. (2011). Children's books for use in bibliotherapy. Journal of Pediatric Health Care, 25, 57-61.

Graneheim, U.H., \& Lundman, B. (2004). Qualitative content analysis in nursing research: Concepts, procedures and measures to achieve trustworthiness. Nurse Education Today, 24, 105-112.

Greenspan, S.I. (1988). Emotional and developmental patterns in infancy. In C. 
Kestenbaum \& D. Williams (Eds.), Handbook of clinical assessment of children and adolescents (pp. 154-179). New York: NYU Press.

Greenspan, S. I., \& Porges, S. W. (1984). Psychopathology in infancy and early childhood: Clinical perspectives on the organization of sensory and affective-thematic experience. Child Development, 55, 49-70.

Grice, H. (2005). Transracial adoption narratives: Prospects and perspectives. Meridians: Feminism, race, transnationalism, 5, 124-148.

Grotevant, H.D., Dunbar, N., Kohler, J.K., \& Esau A.M. (2000). Adoptive identity: How contexts within and beyond family shape developmental pathways. Family Relations, 49, 379-387.

Holt International. (2011). International adoption statistics. Retrieved January 2, 2012 from http://www.holtinternational.org/instats.shtml.

Hsieh, H.F., \& Shannon, S.E. (2005). Three approaches to qualitative content analysis. Qualitative Health Research, 15, 1277-1288.

Janning, M., Collins, C., \& Kamm, J. (2011). Gender, space, and objects in divorced families. Michigan Family Review, 15, 35-58.

Jue-Steuck, J. (2011, February). Rebirthing the nation: How transnational adoption bridges the motherline and mirrors social capital across communities. Paper presented at the Society for Cross Cultural Research Conference, Charleston, SC.

Kavanaugh, C., \& Fiorini, J. (2009, March). Uses of bibliotherapy for adoptive children and their families. Paper presented at the American Counseling Association Annual Conference, Charlotte, NC.

Kelly, M. (2002). Reflections on "John Q": Simple message, missing perspectives. Michigan Family Review, 7, Retrieved June 4, 2011 from http://quod.lib.umich.edu/m/mfr/4919087.0007.106?rgn=main;view=fullte xt.

Kennedy, P. (2006). A story about adoption A sister for Matthew. Nashville TN: GPKids.

Kranstuber, H., \& Kellas, J. (2011). "Instead of growing under her heart, I grew in it": The relationship between adoption entrance narratives and adoptees' self-concept. Communication Quarterly, 59, 179-199.

Lebner, A. (2000). Genetic "mysteries" and international adoption: The cultural 
impact of biomedical technologies on the adoptive family experience. Family Relations, 49,371-377.

Leon, I. G. (2002). Adoption losses: Naturally occurring or socially constructed? Child Development, 73, 652-663.

Lindholm, T., Sjöberg, R., Pedroletti, C., Boman, A., Olsson, G., Sund, A., \& Linblad, F. (2009). Infants' and toddlers' remembering and forgetting of a stressful medical procedure. Journal of Pediatric Psychology, 34, 205216.

Little Miracles Adoption Services. (2012). Children's books - adoption and international adoption. Retrieved January 21, 2012 from http://www.littlemiracles.org/index.php?page=bookstore\&catid=4.

McDevitt, T., \& Ormrod, J. (2007). Child development and education. Boston, MA: Prentice Hall/Pearson.

Miall, C. E. (1987). The stigma of adoptive parent status: Perceptions of community attitudes toward adoption and the experience of informal social sanctioning. Family Relations, 36, 34-40.

Murphy, N. (2009). Facilitating attachment after international adoption. MCN: The American Journal of Maternal Child Nursing, 14, 210-217.

Pang, V., Han, P., \& Pang, J. (2011). Asian American and Pacific Islander students: Equity and the achievement gap. Educational Researcher, 40, 378-389.

Parents' Magazine. (2012). Children's books about adoption. Retrieved January 21, 2012 from http://www.parents.com/parenting/adoption/facts/childrensbooks-about-adoption.

Patton, M. (2002). Qualitative research and evaluation methods. Thousand Oaks, CA: Sage.

Pinderhughes, E. (1996). Toward understanding family readjustment following older child adoptions: The interplay between theory generation and empirical research. Children and Youth Services Review, 18, 115-138.

Ponte, I.C., Wang, L.K., \& Fan, S.P. (2010). Returning to China: The experience of adopted Chinese children and their parents. Adoption Quarterly, 13, 100-124. 
Raible, J. (2008). Real brothers, real sisters: Learning from the white siblings of transracial adoptees. Journal of Social Distress and the Homeless, 17, 87105.

Rathbun, C., \& Kolodny, R. (1967). A groupwork approach in cross-cultural adoptions. Children, 14, 117-121.

Roethler, J. (1998). Reading in color: Children's book illustration and identity formation for black children in the United States. African American * Review, 32, 95-105.

Royle, D. (Executive Producer). (2004). National Geographic's Ultimate Explorer - China's lost girls [Television broadcast]. Washington, DC: National Geographic Broadcasting Company.

Rumford, C. (2008). Social policy beyond fear: The globalization of strangeness, the 'War on Terror', and 'Spaces of Wonder'. Social Policy \& Administration, 42, 630-644.

San Román, B. (2011, February). "I am White... even if I am racially Black"; "I am Afro-Spanish"; Subjectivation and identification in transracial adoptions: Between queer and third space. Paper presented at the Society for Cross Cultural Research Conference, Charleston, SC.

Song, L.T. (2004). Rice paddy to Kung Fool Mask: Race and cultural awareness in international and transracial adoption communities. Michigan Family Review, 9, 11-18.

Suter, E. (2008). Discursive negotiation of family identity: A study of US families with adopted children from China. Journal of Family Communication, 8, 126-147.

Taylor, F. (2003). Content analysis and gender stereotypes in children's books. Teaching Sociology, 31, 300-311.

Tessler, R., Han, B., \& Hong, J. (2005). The racial attitudes of Chinese adoptees in America: Comparisons with children being raised in China. International Journal of Child \& Family Welfare, 2-3, 127-135.

Von Korff, L., Grotevant, H., Koh, B., \& Samek, D. (2010). Adoptive mothers: Identity agents on the pathway to adoptive identity formation. Identity: * An International Journal of Theory, 10, 122-137. 
Wegar, K. (2000). Adoption, family ideology, and social stigma: Bias in community attitudes, adoption research, and practice. Family Relations, 49, 363-370.

White, M. M. (2005). Familial influence in the autobiographies of Black South African and African American women activists. Michigan Family Review, 10, 27-44.

Winkle-Wagner, R. (2009). The perpetual homelessness of college experiences: Tensions between home and campus for African American women. The Review of Higher Education, 33, 1-36. International Adoption Children's Book List.

\section{Book Sample References}

Barrett, L. (2009). My new mommy I got adopted! Mustang, OK: Tate.

Busby, R. (2005). Carson's book A story about adoption from China. Bloomington, IN: Author House.

Coste, M. (2006). Finding Joy. Honesdale, PA: Boyds Mills Press.

Cumings, M. (2006). Three names of me. Morton Grove, IL: Albert Whitman \& Company.

Davies Okimoto, J. \& Aoki, E. M. (2002). The White Swan Express a story about adoption. New York: Clarion Books.

Kennedy, P. (2006). A story about adoption A sister for Matthew. Nashville TN: GPKids.

Kitze, C.A. (2003). We see the moon. Warren, NJ: EMK Press.

Koh, F. M. (2000). A China adoption story Mommy, why do we look different? Minneapolis, MN: EastWest Press.

Lewis, R. (2000). I love you like crazy cakes. New York: Little, Brown and Company.

Lewis, R. (2007). Every year on your birthday. New York: Little, Brown and Company.

McMahon, P. \& McCarthy, C.C. (2005). Just add one Chinese sister. Honesdale, PA: Boyds Mills Press. 
Miceli, M.A. (2009). China baby doll. Bloomington, IN: Xlibris.

Molnar-Fention, S. (1998). An Mei's strange and wondrous journey. New York: Melanie Kroupa Book.

Oelschlager, V. (2008). Made in China A story of adoption. Akron, OH: Vanita Books.

Peacock, C.A. (2000). Mommy far, Mommy near An adoption story. Morton Grove, IL: Albert Whitman \& Company.

Petertyl, M.E. (1997). Seeds of love For brothers and sisters of international adoption. Grand Rapids, MI: Folio One.

Regier, D. (2004). The long ride a child's search/a family's search. Grand Rapids, MI: Kregel Kidzone.

Schaumberg, R. M. \& Schaumberg, E.R. (2007). Three blessings from China adopted. Bloomington, IN: AuthorHouse.

Shemin, C. (2003). Families are forever. Montauk, NY: As Simple As That.

Spangler, J. (2008). The sky princess. Denver, CO: Outskirts Press.

Spangler, J. (2009). The sky princess moves to the land of peaches. Bloomington, IN: Author House.

Stoeke, J.M. (2005). Waiting for May. New York: Puffin.

Thomas, E. (2004). The red blanket. New York: Scholastic Press.

Young, E. (2006). My Mei Mei. New York: Philomel Books. 